Annual Review of Nuclear Science

Vol. 7. Edited by James G. Beckerley, in association with Robert Hofstadter and Leonard I. Schiff Pp. viii +496. (Palo Alto, Calif.: Annual Reviews, Inc., 1957. Published in co-operation with the National Research Council of the National Academy of Sciences.) 7 dollars.

VOLUME 7 of the "Annual Reviews of Nuclear Science" contains the following twelve contributions : Mu-Meson Physics, J. Rainwater; Radiochemical Separations by Ion Exchange, K. A. Kraus and F. Nelson; Equipment for High Level Radiochemical Processes, N. B. Garden and E. Nielsen; Cellular Radiobiology, E. L. Powers; Biochemical Effects of Tonizing Radiation, B. E. Holmes ; Vertebrate Radiobiology (Lethal Actions and Associated Effects), V. P. Bond and J. S. Robertson; Vertebrate Radiobiology (The Pathology of Radiation Exposure), C. C. Lushbaugh; The Collective Model of Nuclei, F. Villars; Nuclear and Nucleon Scattering of HighEnergy Electrons, $\{$ R.Hofstadter; Collision of $\lesssim 1 \mathrm{BeV}$. Particles (excluding Electrons and Photons) with Nuclei, S. J. Lindenbaum ; The Measurement of the Nuclear Spins and Static Moments of Radioactive Isotopes, W. A. Nierenberg; Hyperons and Heavy Mesons (Systematics and Decay), M. Gell-Mann and A. H. Rosenfeld.

The articles in this volume are up to the very high standard which we have come to expect in this series. Most of them represent excellent up-to-date surveys which, in different ways, should be equally valuable to the expert or the new research student who wants a readable introduction to a new field and is overwhelmed by the published literature. The review by Rainwater and, to a much lesser extent, that by Gell-Mann and Rosenfeld were written at an inopportune time. They were concluded within a few months of the discovery of parity violation in weak interactions, when these subjects were in a state of violent change. As a result, much experimental work done since their completion is missing from these surveys and theoretical conjectures based on conflicting or sparse data would be on sounder foundation to-day.

It would seem most desirable to be able to buy individual articles (friends of authors may already be lucky enough to receive such complimentary copies) at a small fraction of the present price.

\section{F. MANDL}

\section{Nuclear Chemical Engineering}

By Prof. Manson Benedict and Prof. Thomas $H$. Pigford. (McGraw-Hill Series in Nuclear Engineering.) Pp. xiv +594. (London : McGraw-Hill Publishing Company, Ltd., 1957.) 7ls. $6 d$.

A

WIDE interpretation of the title is possible, but the authors have made it clear that they are concerned with the materials of importance in nuclear reactors and the novel processes which have been developed to concentrate, purify, and separate them. The use of nuclear radiations in processing materials is not dealt with.

The strength of the book lies in its very thorough theoretical treatment of the various flow sheets which have either been developed or grown in importance as a result of the growth of nuclear power. On this subject the reader will expect much from two such distinguished authors, and he will not be disappointed.

The thermal nuclear reactor is treated simply as a chemical engineering process and, rightly, no attempt has been made to summarize the theory of nuclear reactors. Fuel flow sheets are developed for a typical reactor. Although the principles are well presented, a more critical review of the effects of the assumptions on the results would be welcomed.

Two chapters deal with the production and properties of uranium, zirconium, thorium and beryllium, but no mention is made of graphite. There is an excellent description of solvent extraction processes.

The chemical and radioactive properties of irradiated fuel receive adequate treatment, as does the separation of reactor products. A very thorough and well-written account of the theory of isotope separation and applications is given.

The production is good except for the poor photographs. The authors' wide experience of industry and university has resulted in the production of a first-class book which is highly recommended.

\section{W. Murgatroyd}

Progress in Biophysics and Biophysical Chemistry Vol. 8. Edited by Prof. J. A. V. Butler and Prof. B. Katz. (Progress Series.) Pp. viii +409 . (London and New York: Pergamon Press, 1957.) 105s. net.

7 HIS volume has four articles on various aspects of protein synthesis and the nucleic acids, and five others on hearing, colour vision, bacterial electro. chemistry, the nerve axon and red cell permeability. No doubt they will all be of value, and some will certainly be of great value, to specialists in these fields. But it is not to this clientele that the editors say they address themselves. They aim higher and "believe that collections of critical reviews of this kind will help to provide a meeting ground for all those scientists who, in spite of their very different methods of approach, are concerned with the applications of physical principles to biology".

In judging their success it must not be forgotten that the scientific reader out to widen his acquaintance is an extremely shy person. In a good deal of the book, unfortunately, the approach is not likely to charm his hesitancy. We can scarcely blame the editors for this, for it is notoriously difficult to extract from the expert a critical account of the fundamental facts and ideas current in his subject, and to get it written in sufficiently attractive and explicit language to be interesting and intelligible to his scientific neighbours. Rather we must be grateful to them, and count their book a success, for the two or three outstanding articles it contains which do possess the rare qualities needed to make friends and influence people.

P. A. Merton

\section{An Introduction to Probability Theory and Its Applications}

Vol. 1. By Prof. William Feller. Second edition. (Wiley Publications in Statistics.) Pp. xv +461 . (New York : John Wiley and Sons, Inc.; London : Chapman and Hall, Ltd., 1957.) 86s. net.

7 THIS, the second edition of Prof. Feller's well-

known book, contains a new chapter on "Fluctua. tions in Coin Tossing and Random Walks", and in it results obtained earlier by advanced methods are now deduced by elementary means. Throughout the book there is increased emphasis on waiting times.

There is a rather remarkable aspect of duality pervading the account. The theory of probability is developed with a degree of rigour which should satisfy the pure mathematician. But there are also applica- 